\title{
Research on Incentive Mode of New Generation Employees in State-Owned Enterprises
}

\author{
Youjun $\mathrm{Wu}^{1,{ }^{1}}$ Jingying $\mathrm{Lian}^{1}$ and Peijie $\mathrm{Hu}^{1}$

\begin{abstract}
${ }^{1}$ Evergrande School of Management, Wuhan University of Science and Technology, Wuhan, Hubei 430081, China *Corresponding author.Email: 656152185@qq.com
\end{abstract}

\begin{abstract}
This paper aims to solve the problem that the inherent incentive methods of state-owned enterprises cannot meet the needs of new generation employees and propose ways to innovate the new generation staff incentive methods and improve the incentive structure. This paper uses the literature review method, questionnaire survey method, and statistical analysis method to conduct a questionnaire survey on the new generation of employees; analyzes the incentive methods selected by the new generation of employees in four dimensions: material level, security, and safety level, social level and self-actualization level. puts forward on improving suggestions of relevant mechanism for the four dimensions of incentive factors according to the analysis results and combined with the actual characteristics of state-owned enterprises, to improve the enthusiasm of the new generation of employees, reduce the turnover rate and enhance the core competitiveness of enterprises.
\end{abstract}

Keywords: state-owned enterprise, new generation employees, incentive

\section{INTRODUCTION}

The 21st century is the era of the "Internet plus". Globalization has broken the limitations of the original development pattern of enterprises and impacted the inherent human resource management pattern of enterprises. Excellent talents and diverse management models are essential for the sustainable development of enterprises, and human resource management plays an important role in it. Hansford (2015) defines the new generation of employees as the employee group from the 1980 s to the early 21 st century [1]. Yang Wei (2016) believes that the new generation of employees are those born from the $1980 \mathrm{~s}$ to the $1990 \mathrm{~s}$, that is, those born between 1980 and 1995 [2]. Based on the research results of scholars at home and abroad, this paper defines the new generation of employees as those born after 1990. At present, the proportion of new generation employees is gradually increasing and becoming the backbone of the enterprise.

State-owned enterprises have been attracting employees with the incentive mechanism of good benefits, but there are still problems such as redundancy and poor efficiency. And today, when the new generation employees are becoming the main force, these incentives are far from meeting the needs. State-owned enterprises must follow the trend and change the incentive strategy to better retain the new generation employees.

\section{SURVEY ANALYSIS OF THE NEW GENERATION EMPLOYEES INCENTIVE IN STATE-OWNED ENTERPRISES}

\subsection{Basic Information of the Questionnaire}

The questionnaire design of this survey was based on the original motivation theory research and existing scales, and the final questionnaire was determined after several analyses and modifications in the context of the current corporate incentive mechanism. The target population of this study is mainly the "post-90s", that is, people born in the $1990 \mathrm{~s}$ and after. The questionnaire divided the respondents into three characteristics: gender age and qualifications. Returned a total of 168 questionnaires. The sample structure of the questionnaire is shown in Table 1.

Table 1 Sample structure of the questionnaire

\begin{tabular}{|c|c|c|c|}
\hline \multirow{2}{*}{ Gender } & Male & 55 & $32.74 \%$ \\
\hline & Female & 113 & $67.26 \%$ \\
\hline \multirow{3}{*}{ Age } & Post-90s & 45 & $26.79 \%$ \\
\hline & Post-95s & 79 & $47.02 \%$ \\
\hline & Post-00s & 44 & $26.19 \%$ \\
\hline \multirow{4}{*}{ Qualification } & $\begin{array}{l}\text { High school/secondary } \\
\text { school or below }\end{array}$ & 5 & $2.98 \%$ \\
\hline & Junior college & 21 & $12.5 \%$ \\
\hline & Undergraduate & 105 & $62.5 \%$ \\
\hline & $\begin{array}{c}\text { Master degree and } \\
\text { above }\end{array}$ & 37 & $22.02 \%$ \\
\hline
\end{tabular}




\subsection{Analysis of Survey Results}

\subsubsection{Employee incentive problems of state- owned enterprises}

There are many problems in the current incentive mechanism of state-owned enterprises. The common problems were set in the questionnaire by collecting the data. And the opinions of the younger generation on these problems were obtained through the survey. The results of 168 questionnaires are shown in Table 2.

Table 2 Problems of employee incentive in state-owned enterprises

\begin{tabular}{|l|c|c|}
\hline \multicolumn{1}{|c|}{ Existing problem } & Subtotal & Proportion \\
\hline $\begin{array}{l}\text { A. The incentive form is too } \\
\text { single, material incentive and } \\
\text { spiritual incentive cannot be } \\
\text { effectively combined }\end{array}$ & 110 & $65.48 \%$ \\
\hline $\begin{array}{l}\text { B. Lack of normative } \\
\text { measures for incentive and } \\
\text { the incentive is not targeted }\end{array}$ & 111 & $66.07 \%$ \\
\hline C. There is inequity & 93 & $55,36 \%$ \\
\hline D. Untimely incentive & 64 & $38.1 \%$ \\
\hline
\end{tabular}

According to the survey results, the new generation employees think that the main incentive problems of stateowned enterprises are the irregularity of the mechanisms and the monotony of the methods. The incentive is divided into long-term and short-term, material and spiritual incentive. Enterprises must pay attention to both short-term and long-term incentives, while material and spiritual incentives are complementary.

According to the results of the questionnaire, the first problem of the incentive mechanism in state-owned enterprises is that the incentive measures are not standardized and lack relevance. This problem mainly reflects that state-owned enterprises do not have a perfect performance appraisal system. Performance appraisal is the most common and effective incentive in the incentive mechanism. By linking the results of employee performance appraisal and performance compensation, to promote employees to work hard.

Employees complete their work at different levels, but there is no clear performance appraisal system. Employees cannot obtain rewards for the excellent degree of completing tasks, failing to improve their enthusiasm and reduce their work efficiency. Employees are unable to obtain rewards for their excellence in completing tasks, failing to improve their enthusiasm and lower work efficiency.

Secondly, the incentive methods of state-owned enterprises are monotonous, mainly through short-term material incentives such as bonuses, and fail to combine spiritual and material incentives, long-term and short-term incentives. For the new generation employees nowadays, the incentive effect of simply attracting and stimulating employees through money and materials is one-sided and prone to marginal effects. Moreover, the salary distribution of state-owned enterprises is controlled by the superior units and has certain restrictions, which means that the material incentives, such as bonuses, may also not have core competitiveness in the salary market. Compared with some foreign enterprises and newborn Internet enterprises, state-owned enterprises are far from investing enough in spiritual incentive. Role model, honor, and cultural incentive are rare, and spiritual incentive is very weak. The long-term incentive system is not mature enough and most employees are receiving "fixed salary". Long-term incentives such as equity incentives and corporate dividends are not popular and difficult to implement, so the incentive mechanism is single and solid.

\subsubsection{Findings on incentive-related issues}

The questionnaire divided common incentive factors into four dimensions, namely: material aspects, security aspects, social aspects, and self-actualization aspects. The questionnaire was set up as shown in Table 3.

Table 3 Incentive factors questionnaire

\begin{tabular}{|c|c|c|}
\hline \multirow{15}{*}{$\begin{array}{l}\text { How important do you } \\
\text { think the following } \\
\text { incentives are? }\end{array}$} & \multirow{4}{*}{ Material aspect } & Salary \\
\hline & & Paid vacation \\
\hline & & Reasonable work breaks \\
\hline & & Bonus awards for individual contributions \\
\hline & \multirow{2}{*}{ Security aspect } & Good working conditions and working environment \\
\hline & & Five social insurance and one housing fund \\
\hline & \multirow{4}{*}{ Social aspect } & Company league building \\
\hline & & Harmonious interpersonal relationship \\
\hline & & Good communication environment \\
\hline & & Sense of belonging in the team \\
\hline & \multirow{5}{*}{ Self-actualization aspect } & Individual contributions are praised \\
\hline & & Work is recognized by colleagues and leaders \\
\hline & & Feedback on individual comments and suggestions \\
\hline & & Respect for personal thoughts and behaviors \\
\hline & & Challenging work \\
\hline
\end{tabular}


This questionnaire adopts a five-point Likert scale to classify various incentive factors into five levels: "Most important", "Very important", "Generally important", "Not very important", and "Unimportant". 168 respondents completed the questionnaire to explain the importance of these incentives to themselves. The results of the questionnaire are shown in Table 4.

Table 4 Statistical table of questionnaire results of incentive factors (unit: persons)

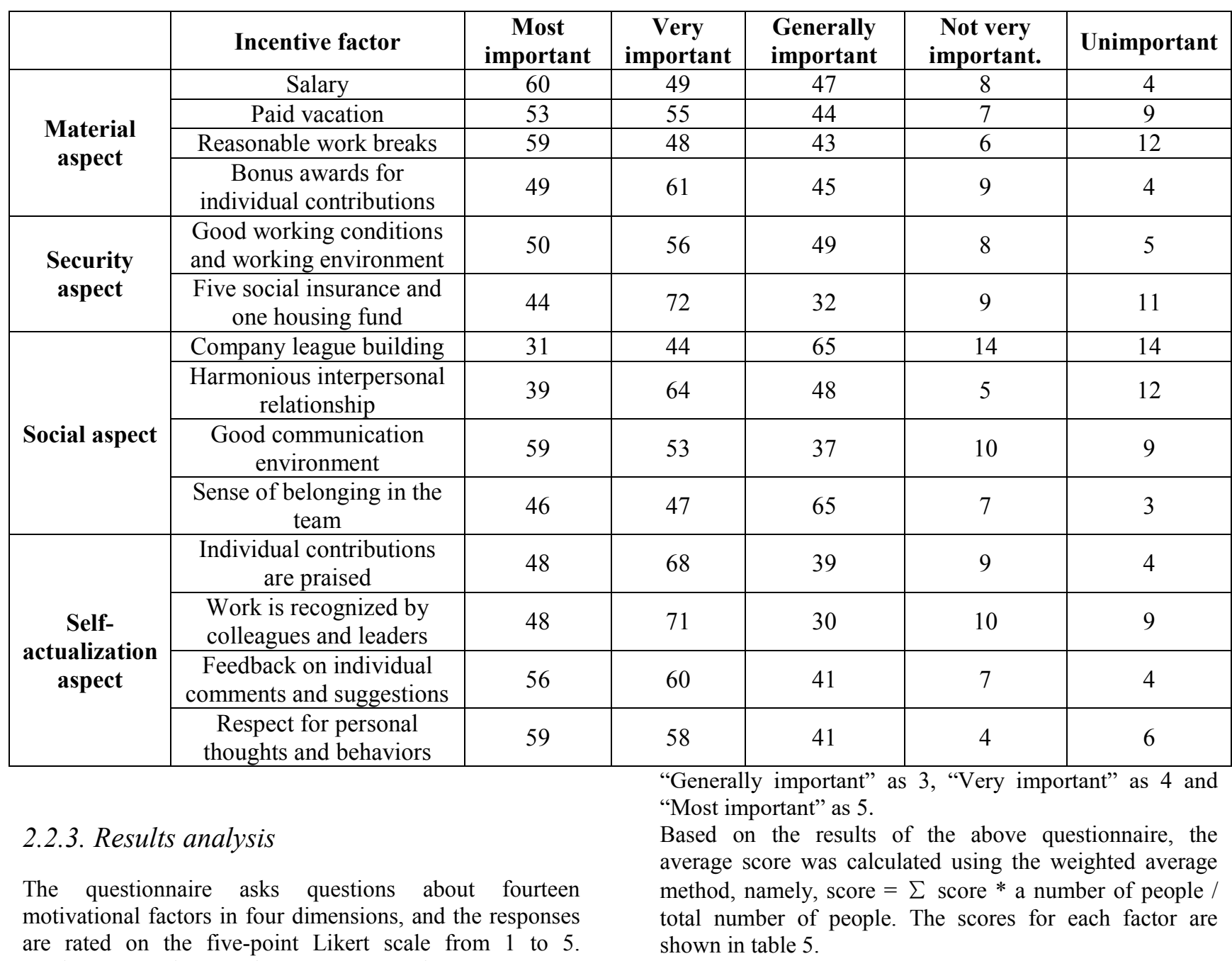

Table 5 Statistical table of incentive questionnaire score

\begin{tabular}{|c|c|c|c|}
\hline Dimension & Factor & Score & Total \\
\hline \multirow{4}{*}{ Material aspect } & Salary & 3.81 & \multirow{4}{*}{3.84} \\
\hline & Paid vacation & 3.85 & \\
\hline & Reasonable work breaks & 3.91 & \\
\hline & Bonus awards for individual contributions & 3.81 & \\
\hline \multirow{2}{*}{ Security aspect } & Good working conditions and working environment & 3.82 & \multirow{2}{*}{3.79} \\
\hline & Five social insurance and one housing fund & 3.77 & \\
\hline \multirow{4}{*}{ Social aspect } & Company league building & 3.38 & \multirow{4}{*}{3.66} \\
\hline & Harmonious interpersonal relationship & 3.67 & \\
\hline & Good communication environment & 3.85 & \\
\hline & Sense of belonging in the team & 3.75 & \\
\hline \multirow{2}{*}{ Self-actualization aspect } & Individual contributions are praised & 3.88 & \multirow{2}{*}{3.87} \\
\hline & Work is recognized by colleagues and leaders & 3.83 & \\
\hline
\end{tabular}




\begin{tabular}{|c|c|c|c|}
\hline \multirow{2}{*}{} & Feedback on individual comments and suggestions & 3.93 & \\
\cline { 2 - 4 } & Respect for personal thoughts and behaviors & 3.95 & \\
\hline
\end{tabular}

The questionnaire results were analyzed based on a Likert scale, and the results showed that the importance of the four incentive dimensions of the new generation employees was rated as self-actualization $>$ Material aspect $>$ Security $>$ Social.

For the first three dimensions of motivational factors, the importance ratings were relatively high. Material incentives and security incentives are the most common and basic incentives in the enterprise, and it is obvious that this part is rated higher. For these two parts, incentive investment is high, but it is easy to produce a "marginal effect". For these two parts, the incentive input is high, but it is easy to produce a "marginal effect". Frequent material rewards such as bonuses, vacations, etc. can increase the incentive of employees for a short time, but too frequent use of this method will reduce the incentive effect. And the material incentive increase is "deserved" for employees, but once the material incentive is reduced, it is easy to make employees "rebel" and play a negative role. Social motivation is mainly to create a good working atmosphere and drive all employees to work actively through the overall upward atmosphere. For state-owned enterprises, it will take a long time to change. Table 3.2 shows that "redundant and inefficient" is a characteristic of stateowned enterprises, which is caused by historical characteristics. It also needs to be changed from the spiritual and cultural construction.

The new generation employees attach the highest importance to self-actualization, with a score of 3.87 . This result reflects the characteristics of the new generation employees, and also confirms with the previous research results that self-realization includes the realization of selfvalue and the need for self-respect. Most of the new generation employees grow up in " 124 " families. And the particularity of the times leads them to value themselves more. The realization of self-value is a very important part of their spiritual incentive. They long to do challenging work and hope to get recognition in their work, which will make them get spiritual satisfaction. By satisfying the spiritual incentive desire of the new generation employees, their work enthusiasm can be greatly increased. This research conclusion has great reference significance for the incentive reform of state-owned enterprises.

\section{IMPROVEMENT MEASURES AND SUGGEATIONS}

\subsection{Improving the Compensation and Welfare System}

The first thing is to establish a transparent and fair compensation and benefits system. Companies should develop a fair compensation management process and provide new generation employees with both internal and external fair compensation and benefits to ensure that employees are paid for their work after they have completed their duties, thus motivating them to work. In addition to the basic salary, employees should be provided with non-monetary forms of material incentives. Through various implicit benefits to bridge the gap with private companies and improve the attractiveness to new generation employees. Secondly, a fair and transparent salary system is conducive to guiding healthy competition among colleagues. According to the positive psychological characteristics of the new generation of employees, and in their need to achieve self-worth, a fair and transparent salary system can create a harmonious competitive working atmosphere within the enterprise and realize a good competitive working environment.

Due to their characteristics, the new generation of employees values salary, welfare, rituals. Welfare is also a point that post-90s employees care about a lot, and it is also a point that is extremely different from post-70s and post80 s employees. As for the welfare requirements of post- $90 \mathrm{~s}$ employees, they pay most attention to holidays and travel, so companies can hold regular team travel and build up a flexible leave system. post-90s employees also attach relative importance to each holiday, so companies can send small gifts on that day to make employees feel warm. In other aspects, providing gym, housing discount, free afternoon tea, etc. will bring satisfaction to post-90s employees and motivate them to work actively.

\subsection{Establishing a Standardized Performance Appraisal System}

In addition to improving the compensation and welfare mechanism, enterprises should also develop a standardized performance appraisal system and establish detailed performance appraisal standards and scoring rules. When formulating the performance appraisal system, the company should develop a performance appraisal system that is suitable for employees and can be implemented through analysis and discussion based on the different work nature and job responsibilities of employees.

Clear performance standards and timely performance feedback are effective ways to provide adequate work challenges to incumbent employees. Unclear goals, vague objectives, and poor communication can lead to low motivation and, ultimately, poor performance. Showing performance appraisal results through intuitive scores, linking appraisal scores directly to employees' performance pay, and using them as a reference standard for employee promotion and merit evaluation, to reward the best and punish the worst and achieve motivational purposes. And the appraisal can take a variety of forms, not confined to the simple superior evaluation of subordinates, to enrich the assessment content assessment methods, to increase the reliability of performance appraisal [3]. 
Finally, the system of firmly implementing all the assessment results, setting salary by post and compensation by job performance, and gaining additional incentives through personal ability. Adequately combining positive and negative incentives can effectively mobilize employees' work motivation and promote the benign development of the enterprise.

\subsection{Strengthening Spiritual Incentive of New Generation Employees}

To meet the inner development needs of the new generation employees, firstly, enterprises can build spiritual culture. Such as psychological counseling lectures, team building, establishing a good working atmosphere, and maintaining a good interpersonal relationship with colleagues. In addition, through the construction of corporate culture, enterprises can make employees have a sense of belonging. It is also possible to listen to the views and suggestions of new generation employees in their daily work so that employees can feel that they are recognized and realize the unity of new generation employees' recognition of their work and their sense of selfsatisfaction, thus promoting the stable improvement of new generation employees' loyalty [4]. Secondly, to meet the needs of the new generation employees to improve their self-ability. The new generation employees are willing to engage in challenging work and hope to improve their abilities while completing their work. This is the selfrealization need mentioned in Maslow's needs analysis theory, and it is necessary to meet this part of the incentive needs of the new generation employees. Enterprises can rely on various ways of staff training to achieve this. On the one hand, staff training can improve their ability, make them obtain self-satisfaction and improve their work enthusiasm. On the other hand, it is also conducive to improving the core competitiveness of enterprises to promote enterprise development. By carrying out a variety of job training, employees are prompted to develop the correct concept of lifelong learning, so that they can realize their self-value in the enterprise, strengthen their sense of belonging to the enterprise, thus effectively improving the quality of human resource management in state-owned enterprises [5].

\section{CONCLUSIONS AND PROSPECTS}

Based on the contemporary characteristics of the new generation employees and the related literature on incentive mechanism. This paper prepares a questionnaire for the new generation employees of state-owned enterprises and explores the problems of the incentive mechanism. And based on these problems, the incentive factors are divided into the material dimension, security dimension, interpersonal dimension, and self-actualization dimension, and suggestions for the improvement of incentive mechanism are proposed. It not only has some reference significance for state-owned enterprises to understand the new generation employees, but also provides a reference basis for the reform of incentive mechanism of enterprises.

However, due to the limitation of the research conditions and the lack of personal experience and ability, there are some shortcomings in this study: The sample size of the questionnaire survey collection is small, the content of the questionnaire is not comprehensive enough, the proposed incentives are not specific enough, and the enforceability of these incentives is open to further discussion.

\section{REFERENCES}

[1] Hansford. D. Insights into managing an age-diverse workforce [J]. Workspan, 2006(6), pp.45.

[2] Yang Wei, "A study on the loyalty of new generation employees - based on the perspective of twofactor theory", BUSINESS, 2016, pp. 24.

[3] Yang Ningyi, "Study on the impact of incentive mechanism on the loyalty of new generation employees", Modern Business Trade Industry, 2021, pp. 66-68. DOI:10.19311/j.cnki.1672-3198.2021.04.029

[4] Chen Wen and Kong Qingmin, “Analysis of management training problems and countermeasures for the new generation of "post-90s" employees", Enterprise Science And Technology \& Development, 2021, pp. 163-165. DOI:10.3969/j.issn.16740688.2021.01.060

[5] Li Yiwei. "Research on human resource management problems and countermeasures for the new generation of "post-90s" employees", Rural Economy and Science-Technology, 2021, pp. 158-159,18 